Original Article

\title{
Predisposing Factors and Surgical Management of Obstructive Sleep Apnoea in Children
}

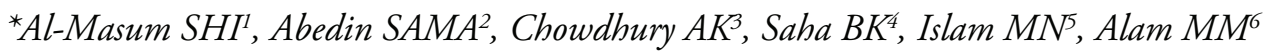

\section{Abstract}

Obstructive sleep apnoea (OSA) is a condition characterized by episodic partial or complete obstruction of the upper airway during sleep. This cause apnoea or cessation of breathing. During sleep, muscles around the airway relax causing the throat and upper airway to narrow. This leads to snoring, but it can also lead to the airway being blocked. Trying to breathe against a blocked airway causes oxygen levels to fall and carbon dioxide to rise. This cross-sectional study was conducted in Department of ENT, Dhaka Shishu (Children) Hospital and Dhaka Medical College Hospital from April to September'2015. The purpose of the study was to prevent significant morbidity and enhancement of child growth. One hundred children of OSA were studied by detail history and clinical examination. All children whose parents consulted their ENT surgeon in Dhaka Shishu(Children) Hospital and $D M C H$ for snoring or laboured breathing during sleep (nocturnal sweating particularly in the nuchal area, unusual sleeping positions, restless sleep, awakening and excessive movements, intercostals recession and dry mouth) were included in the study. More common predisposing conditions for OSA were obesity and Craniofacial anomalies which were $34 \%$ and $27 \%$ respectively. In present study most of the children (73\%) were managed by Adenotonsillectomy and $27 \%$ children were manage by Adenoidectomy. Outcome data have demonstrated that surgical therapy can be successful in the treatment of OSA.

Key words: Obstructive sleep apnoea, enlarged adenoid or enlarge adenoid and tonsil

1. * Prof. (CC) Dr. Syed Hasan Imam Al-Masum, Professor of ENT Department Dhaka Shishu (Children) Hospital. Cell Ph: +8801711141543

2. Syed A. M Asfarul Abedin, Associate professor, Department of ENT, Brahmanbaria Medical College Hospital.

3. Dr. Anup Kumar Chowdhury, Registrar, Dhaka Medical College Hospital

4. Dr. Bishwojit Kumar Saha, Registrar, Dhaka Medical College Hospital

5. Professor Md. Nazmul Islam, Professor Department of ENT, Dhaka Medical College Hospital

6. Dr. Md. Mahbub Alam, Associate Professor, Department of ENT, Ad-din Women's Medical College Hospital, Dhaka.

*For Correspondence

\section{INTRODUCTION}

Obstructive sleep apnoea (OSA) is one of the most common causes of sleep-disordered breathing (SDB) in children. It is associated with significant morbidity, potentially impacting on long-term neurocognitive and behavioural development, as well as cardiovascular outcomes and metabolic homeostasis. ${ }^{1}$ The prevalence of OSA has been estimated to be $14 \%$ of men and $5 \%$ of women, in a population-based study utilizing an apnoea and hypopnoea index (AHI) cutoff of $\geq 5$ events/h (hypopnoeas associated with $4 \%$ oxygen desaturations) combined with clinical symptoms to define OSA. ${ }^{2}$ The prevalence of OSA is substantially higher than this estimate, for example, in patients being evaluated for bariatric surgery (estimated range of $70 \%$ to $80 \%)^{3}$ or in patients who have had a transient ischemic attack or stroke (estimated range of $60 \%$ to $70 \%) .^{4}$ Other disease-specific populations found to have increased rates of OSA include, but are not limited to, patients with coronary artery disease, congestive heart failure, arrhythmias, refractory hypertension, type 2 diabetes, and polycystic ovarian disease. ${ }^{5,6}$ Obstructive sleep apnea (OSA) is a problem that affects your child's breathing during sleep. An obstruction is a blockage of airflow into the lungs. Apnoea means a pause in breathing for at least 10 seconds. Six seconds or less may be pathological in children. A child (or adult) with obstructive sleep apnea has times during sleep when air cannot flow normally into the lungs. ${ }^{7}$ The immediate consequences of obstructive sleep apnoea syndrome (OSAS) in children include behavioral disturbance and learning deficits, pulmonary hypertension, as well as compromised somatic growth. However, if not treated promptly and early in the course of the disease, OSAS may also impose long term adverse effects on neurocognitive and cardiovascular function, thereby providing a strong rationale for effective treatment of this condition. ${ }^{8}$ Obstructive sleep apnoea (OSA) in children has emerged not only as a relatively prevalent condition but also as a disease that imposes a large array of morbidities, some of which may have long-term implications, well into adulthood. ${ }^{9}$ The major consequences of paediatric OSA involve neurobehavioral, cardiovascular, and endocrine and metabolic systems. The underlying pathophysiological mechanisms of OSA-induced end-organ injury are now being unrevealed, and clearly involve oxidative pathways. ${ }^{9}$ Children with enlarged adenoid and tonsil should be referred for tonsillectomy and 
adenoidectomy. This successfully treats OSA in $80-90 \%$ of children. Children at high risk of postoperative respiratory complications after adenotonsillectomy should have their surgery in centres with expertise in paediatric anaesthesia and paediatric intensive care facilities. ${ }^{10}$ Children who are overweight (obese) would benefit from an exercise and weight management program. Children with chronic nasal allergy may trial a mix of different medical treatments including topical steroid sprays. Children with persisting OSA despite other treatments can be treated with continuous positive airways pressure (CPAP) ${ }^{10}$

\section{MATERIALS AND METHODS}

This observational type of cross-sectional study was conducted department of ENT, Dhaka Shishu (Children) Hospital and Dhaka Medical College Hospital among 100 patients during April to September'2015. All patients with OSA of both sexs and children were included. Mentally Ill patients patients, adult patients were excluded from this study. The purpose of the study to prevent significant morbidity and enhancement of child growth. 100 children of OSA were studied by detail history, clinical examination. This 100 children whose parents consulted their or ENT surgeon in Dhaka Shishu(Children) Hospital and DMCH for snoring or laboured breathing during sleep (nocturnal sweating particularly in the nuchal area, unusual sleeping positions, restless sleep, awakening and excessive movements, intercostals recession and dry mouth) were included in the study. All children had enlarged adenoid or enlarge adenoid and tonsil, which were confirmed by ENT examination. This was also confirmed in all cases by lateral radiography of the nasopharynx and flexible nasoendoscopy. After collection of data, data were edited by meticulous checking and rechecking. SPSS (statistical Package for Social Science) version 23.0 package program was used for analysis of these data. The statistics used to analyze the data were descriptive statistics and tests done were students ' $t$ ' test and $\mathrm{X} 2$ test. Level of significance was set at 0.05 and $\mathrm{p}<0.05$ was considered significant.

\section{RESULTS}

Data were obtained from 100 patients, at the time of the diagnostic sleep study, $32(32 \%)$ patients were less than 5 year, (40\%) were aged 6-10 years, (19\%) were aged 11-15 years, and (9\%) were aged 16-19 years (Table-I). Regarding sex distribution (62\%) boys and (38\%) girls (Table II). More common predisposing conditions for OSA were obesity and Craniofacial anomalies which were $34 \%$ and $27 \%$ respectively (Table-IV). In present study most of the children (73\%) managed by Adenotonsillectomy and 27\% children manage by Adenoidectomy (Table-V).

Table I: Distribution of the study patients by age $(n=100)$

\begin{tabular}{lcc}
\hline Age (in year) & Number of patients & Percentage \\
\hline$\leq 5$ & 32 & 32.0 \\
$6-10$ & 40 & 40.0 \\
$11-15$ & 19 & 19.0 \\
$16-18$ & 09 & 09.0 \\
\hline
\end{tabular}

Table II: Distribution of the study patients according to $\operatorname{sex}(\mathbf{n}=100)$

\begin{tabular}{lcc}
\hline Sex & Number of patients & Percentage \\
\hline Male & 62 & 62.0 \\
Female & 38 & 38.0 \\
\hline
\end{tabular}

Table III: Distribution of the study patients according to obstructive sleep apnea syndrome $(n=100)$

\begin{tabular}{lc}
\hline Obstructive sleep apnea syndrome & Mean \pm SD \\
\hline Total sleep time (min) & $370 \pm 53$ \\
Sleep latenth (min) & $16.2 \pm 14.0$ \\
Awake time after sleep onset (min) & $38.0 \pm 36.1$ \\
No. of rapid eye movement periods & $4.1 \pm 1.2$ \\
Rapid eye movement sleep (\% of total sleep) & $20.5 \pm 5.8$ \\
Sleep efficiency (\%) & $87.1 \pm 8.9$ \\
Arousals per hour of sleep & $2.5 \pm 0.5$ \\
Awakenings per hour of sleep & $0.8 \pm 0.5$ \\
Movements per hour during sleep & $16.9 \pm 12.9$ \\
Breathing during sleep obstructive AHI & $12.1 \pm 7.8$ \\
Sp02 while awake & $98.6 \pm 1.8$ \\
Lowest Sp02 (\%) & $78.4 \pm 13.9$ \\
Peak end-tidal C02 (mmHg) & $56.8 \pm 9.7$ \\
\hline
\end{tabular}

Table IV: Predisposing conditions for OSA in 100 children

\begin{tabular}{lcc}
\hline Predisposing conditions & Number of patients & Percentage \\
\hline Obesity & 34 & 34 \\
Craniofacial anomalies & 27 & 27 \\
Idiopathic & 13 & 13 \\
Sickle cell disease & 03 & 03 \\
Glycogen storage disorder & 04 & 04 \\
Trisomy & 03 & 03 \\
Neuromuscular disease & 05 & 05 \\
\hline Retrognathia and cerebral palsy & 10 & 10 \\
Malformation & 04 & 04 \\
Pharyngeal flap surgery & 05 & 05 \\
Other* & 05 & 05 \\
\hline
\end{tabular}

*Tracheomalacia after tracheal reconstruction in child who had tracheostomy because of laryngeal papillornatosis. 
Table V: Surgical management of the study children $(\mathrm{n}=100)$

\begin{tabular}{lcc}
\hline Surgical treatment & Number & Percentage \\
\hline Adenotonsillectomy & 73 & 73 \\
Adenoidectomy & 27 & 27 \\
Total & 100 & 100 \\
\hline
\end{tabular}

\section{DISCUSSION}

The up to date series implies that obstructive symptoms and signs frequently persist after adenoidectomy alone for treatment of OSA, and that many children who undergo adenoidectomy are not spared tonsillectomy, ${ }^{11,13}$ although a comparison between these two surgical approaches in regards to long-term resolution of OSA symptoms has never been performed. Gov-Ari et al. showed that patients undergoing adenoidectomy for upper airway obstruction are likely to be at an increased risk of subsequent tonsillectomy when compared with those who undergo adenoidectomy for other indications. Young age, female sex, and large tonsil size may further increase the risk for subsequent tonsillectomy. ${ }^{14}$

In present study showed that data were obtained from 100 patients, (62\%) boys and (38\%) girls. At the time of the diagnostic sleep study, $32(32 \%)$ patients were less than 5 year, (40\%) were aged 6-10 years, (19\%) were aged 11-15 years, and (9\%) were aged 16-19 years. Mitchell study observed that the mean age was 6.3 (range, 3.0-14.0) years. ${ }^{15}$ Tang et al. study revealed that the mean time interval between PSG and telephone interview was $3.6 \pm 1.33$ years. The mean age of the cohort was $3.38 \pm 2.61$ years at PSG and $7 \pm 3.03$ at follow-up evaluation. ${ }^{16}$

In current study observed that more common predisposing conditions for OSA were obesity and Craniofacial anomalies which were $34 \%$ and $27 \%$ respectively. Trosman et al studied $^{19}$ of the 62 patients were obese, while 15 had a craniofacial syndrome or hypotonia. ${ }^{17}$ Andersen et al. study observed that OSA was significantly more likely to persist in obese children after adenotonsillectomy. ${ }^{18}$ The prevalence of persistent OSA ranged from $33 \%$ to $76 \%$ in obese children and from $15 \%$ to $37 \%$ in non-obese children depending on the definition of OSA, the degree of obesity and the age of the study population. The few studies that investigated the effect of weight loss found that OSA improved significantly after intervention and that the prevalence of persistent OSA varied between $10 \%$ and $38 \%{ }^{18}$ In present study most of the children (73\%) managed by Adenotonsillectomy and $27 \%$ children manage by Adenoidectomy. In study of Trosman et al observed that Adenotonsillectomy leads to a significant improvement in apnea-hypopnea index. ${ }^{17}$ on follow-up polysomnography over an observational approach, especially in non-obese, non-syndromic children. Mitchell $\mathrm{RB}^{15}$ study observed that the mean total OSA-18 score and the mean scores for all domains showed significant improvement after surgery $(\mathrm{P}<.001)$. Adenotonsillectomy for OSA results in a dramatic improvement in respiratory parameters as measured by polysomnography in the majority of healthy children. Quality of life also improves significantly after adenotonsillectomy for OSA in children. Similar observation was found Tang et al. study revealed that Adenotonsillectomy was performed in 394 children $(76.5 \%)$ and adenoidectomy in $121(23.5 \%) .{ }^{16}$ this study suggests that the indiscriminant approach to perform adenotonsillectomy for all children with OSA who undergo surgery may not be justified. We propose that subjective, long-term outcomes of adenoidectomy are comparable to those of adenotonsillectomy in non-obese children under 7 years old with moderate OSA and small tonsils.

\section{CONCLUSION}

Surgical therapy is an alternative in patients who are intolerant of conservative treatments. Outcome data have demonstrated that surgical therapy can be successful in the treatment of OSA. A careful evaluation of location and cause of airway abnormality and proper selection of patients can result in improved clinical outcome, the patients' quality of life, and general health with minimal complications.

\section{REFERENCE}

1. Dehlink E, Tan HL. Update on paediatric obstructive sleep apnoea. J Thorac Dis 2016;8(2):224-35.

2. Kapur VK, Auckley DH, Chowdhuri S, Kuhlmann DC, Mehra R, Ramar K, Harrod CG. Clinical practice guideline for diagnostic testing for adult obstructive sleep apnea: an American Academy of Sleep Medicine clinical practice guideline. J Clin Sleep Med. 2017;13(3):479-504.

3. Ravesloot MJ, van Maanen JP, Hilgevoord AA, van Wagensveld BA, de Vries N. Obstructive sleep apnea is underrecognized and underdiagnosed in patients undergoing bariatric surgery. Eur Arch Otorhinolaryngol. 2012;269(7):1865-71.

4. Johnson KG, Johnson DC. Frequency of sleep apnea in stroke and TIA patients: a meta-analysis. J Clin Sleep Med. 2010;6(2):131-7.

5. Punjabi NM. The epidemiology of adult obstructive sleep apnea. Proc Am Thorac Soc. 2008;5(2):136-43.

6. Franklin KA, Lindberg E. Obstructive sleep apnea is a common disorder in the population-a review on the 
epidemiology of sleep apnea. J Thorac Dis. 2015;7(8):1311-22.

7. Sockrider M. ATS Patient Education Series, Am J Respir Crit Care Med,2012;180:5-6

8. Andrew J. Lipton and David Gozal, Treatment of obstructive sleep apnea in children: do we really know how? Sleep Medicine Reviews, 2003;7(1):61-80

9. Capdevila OS, Kheirandish-Gozal LK, Dayyat E, and Gozal D. Pediatric Obstructive Sleep Apnea. Proc Am Thorac Soc, 2008;5:274-28

10. Powell S, Kubba H, O'Brien C, Tremlett M. Paediatric obstructive sleep apnoea. BMJ. 2010 Apr 14;340

11. Gozal D, Khreindish L. Disorders of breathing during sleep. In: Chernick V, Boat TF, Wilmott RW, Bush A, eds. Kendig's Disorder of the respiratory tract in children. Elsevier Saunders, 2006:1046-70.

12. Marcus CL, Brooks LJ, Draper KA, et al; American Academy of Pediatrics. Diagnosis and management of childhood obstructive sleep apnea syndrome. Pediatrics 2012;130:e714-55.

13. Paruthi S. Management of obstructive sleep apnea in children. Uptodate 2015; http:/ /www.uptodate. com/contents/management-of-obstructive-sleep-apneain-chil dren.

14. Gov-Ari E, Mills JC, Basler KJ. Predictors of tonsillectomy after previous adenoidectomy for upper airway obstruction. Otolaryngol Head Neck Surg 2012;146:647-52.

15. Mitchell RB1. Adenotonsillectomy for obstructive sleep apnea in children: outcome evaluated by pre- and postoperative polysomnography. Laryngoscope. 2007;117(10):1844-54.

16. Tang AL, Cohen AP, Benke JR, Stierer KD, Stanley J, Ishman SL. Obstructive Sleep Apnea Resolution in Hypopnea- versus Apnea-Predominant Children after Adenotonsillectomy. Otolaryngol Head Neck Surg. 2016;155(4):670-5.

17. Trosman SJ, Eleff DJ, Krishna J, Anne S. Polysomnography results in pediatric patients with mild obstructive sleep apnea: Adenotonsillectomy vs. watchful waiting. Int J Pediatr Otorhinolaryngol. 2016;83:25-30.

18. Andersen IG, Holm JC, Homøe P. Obstructive sleep apnea in obese children and adolescents, treatment methods and outcome of treatment - A systematic review. Int J Pediatr Otorhinolaryngol. 2016;87:190-7. 